\title{
Evidências científicas sobre traumatismos maxilofaciais em mulheres vítima de violência física
}

\author{
Scientific evidence on maxillofacial injuries in women victims of physical violence
}

\author{
Evidencia científica sobre lesiones maxilofacial es en mujeres víctimas de violencia física
}

Eliana Campêlo Lago ${ }^{1}$, Hanna Laila da Silveira Santos², Arthur Gomes Leite ${ }^{2}$, Letícia de Sousa Milanez ${ }^{3}$, Luiz Filipe Lago de Carvalho ${ }^{4}$, Gerardo Vasconcelos Mesquita ${ }^{5}$.

\begin{abstract}
RESUMO
Objetivo: Descrever os principais tipos de traumas maxilofaciais em mulheres vítimas de violência física, sua prevalência e atuação do cirurgião dentista no atendimento das vítimas. Métodos: Este trabalho consiste em uma revisão integrativa de literatura de natureza aplicada, pautada na seguinte questão norteadora: Quais os principais tipos de traumatismos maxilofaciais causados em mulheres vítimas de violência física identificados na literatura? Resultados: Os estudos reportaram a maior prevalência de lesões classificadas como leves, na região maxilofacial, afetando, em sua maioria região de tecidos moles das mulheres vítimas de violência física. A faixa etária estava entre19 a 39 anos, tendo como seu principal agressor seu companheiro ou ex companheiro, sendo o cirurgião dentista, neste cenário, um agente importante para o tratamento e notificação dos casos de violência. Considerações Finais: É reconhecida a relevante problemática da violência de gênero, repercutida de diversas formas na vida da vítima. Destacase a grande prevalência de traumas maxilofaciais em mulheres vítimas de violência inserida em seu contexto, junto ao reconhecimento do protagonismo do cirurgião dentista no cenário intervindo e posicionando-se no combate à violência.
\end{abstract}

Palavras-chave: Violência contra a mulher, Odontologia, Traumatismos maxilofaciais.

\begin{abstract}
Objective: To describe the main types of maxilofacial traumas in women victims of physical violence, its prevalence and the role of surgeon dentists in the care of victims. Methods: This work consists of an integrative literature review of an applied nature, based on the following guiding question: What are the main types of maxillofacial trauma caused in women victims of physical violence identified in the literature? Results: The studies reported the highest prevalence of lesions classified as mild, in the maxillofacial region, mostly affecting the soft tissue region of women victims of physical violence. These are aged between 19 and 39 years old, having as their main aggressor their partner or ex-partner, being the dental surgeon, in this scenario, an important agent for the treatment and notification of cases of violence. Final Considerations: The relevant issue of gender-based violence is recognized, reflected in various ways in the victim's life. We highlight the great prevalence of maxillofacial trauma in women victims of violence inserted in their context, along with the recognition of the role of the dental surgeon in the scenario, intervening and taking a position in the fight against violence.
\end{abstract}

Keywords: Violence against women, Dentistry, Maxillofacial injuries.

\footnotetext{
${ }^{1}$ Universidade Estadual do Maranhão (UEMA) e UniFacid, Teresina - PI. *E-mail: anaileogal@gmail.com

2 UniFacid, Teresina - PI.

3 Universidade Estadual do Piauí (UESPI), Teresina - PI.

4 Universidade de Brasília (UnB), Brasília - DF.

${ }^{5}$ Centro Universitário UNINOVAFAPI, Teresina - PI.
} 


\section{RESUMEN}

Objetivo: Describir los principales tipos de trauma maxilofacial en mujeres víctimas de violencia física, su prevalencia y el papel del dentista en la asistencia a las víctimas. Métodos: Este trabajo consiste en una revisión bibliográfica integradora de naturaleza aplicada, basada en la siguiente pregunta guía: ¿Cuáles son los principales tipos de traumatismos maxilofaciales causados en mujeres víctimas de violencia física identificadas en la literatura? Resultados: Los estudios informaron la mayor prevalencia de lesiones clasificadas como leves, en la región maxilofacial, que afecta principalmente a la región de tejidos blandos de mujeres víctimas de violencia física. Estos tienen entre 19 y 39 años de edad, teniendo como principal agresor a su pareja o ex pareja, siendo el cirujano dental, en este escenario, un agente importante para el tratamiento y la notificación de casos de violencia. Consideraciones finales: Se reconoce la cuestión relevante de la violencia de género, que se refleja de varias maneras en la vida de la víctima. Destacamos la gran prevalencia de trauma maxilofacial en mujeres víctimas de violencia insertadas en su contexto, junto con el reconocimiento del papel del cirujano dental en el escenario, interviniendo y tomando posiciónenla lucha contra la violencia.

Palabras-clave: Violencia contra la mujer, Odontología, Lesiones maxilofaciales.

\section{INTRODUÇÃO}

Segundo a Declaração das Nações Unidas de 1993, a violência contra mulher inclui todo ato violento por razão de gênero, que produz ou pode causar dano físico, sexual, psicológico ou algum tipo de sofrimento diante de ameaças ou privações arbitrária de sua liberdade, independentemente se 0 ato ocorre de forma pública ou em algum local privado. Este fenômeno representa um problema social e de saúde pública complexo, que independe de fronteiras de classe social, raça, etnia, idade e grau de escolaridade (ONU, 1993). A violência contra a mulher tem recebido crescente atenção e mobilização no Brasil. Este problema reflete na saúde e qualidade de vida das mulheres, trazendo consequências à estruturação pessoal, familiar e pessoal (NETTO LA, et al., 2014). É sabido que a violência, além de perdas socioeconômicas ao levar o indivíduo ao adoecimento, sobrecarrega serviços de saúde, compromete o bem-estar, segurança e viola os direitos humanos, podendo levar a vítima ao afastamento do trabalho e da sociedade (KRUCZEWSKI B e PEREIRA RW, 2016).

O aumento de casos de violência de gênero, acompanhado do aumento de denúncias tem aumentado a visibilidade deste fenômeno a sociedade. Dentre os danos causados a essas vítimas, os traumatismos craniomaxilofaciais têm se destacado, devido à face ser um local considerado de maior visibilidade humana. Estes traumas podem gerar sequelas físicas na região da face como: cicatrizes, perdas dentárias, disfunções mastigatórias, além de sequelas emocionais que perduram como lembrança dolorosa do abuso (CHAVES AS, et al., 2018).

No Brasil, a prevalência de traumatismos maxilofaciais causados por violência em mulheres foi compreendida entre $26,3 \%$ e 63,2\% (CHAVES AS, et al., 2018). Dias IJ e Santiago BM (2015) trazem dados que mostraram que $33,4 \%$ das mulheres que procuraram atendimento com traumatismo foram agredidas pelo companheiro. Dados como estes trazem a importância de se conhecer o perfil e as circunstâncias dessas vítimas, na intenção de direcionar os profissionais que a recebam, adequando o atendimento e os serviços prestados na situação de violência.

Dentre os tipos de violência, a violência entre parceiros íntimos se encontra inserida na categoria interpessoal, possui naturezas diversas, podendo ser física, psicológica, sexual e de comportamento controlador. Dentre essas, a forma mais comum contra as mulheres em todo mundo é de ordem física, considerada de complexa discussão, visto que, quando uma mulher se encontra em situação de violência física, provavelmente já sofreu ou sofre dos demais tipos de violência citadas (COELHO EBS, et al., 2014).

A violência contra a mulher é um crime muito frequente, os dados hoje existentes podem ser ainda maiores que os notificados, seja pelo silêncio de muitas mulheres, seja pela subnotificação pelos profissionais de saúde. Para combater este tipo de violência é necessária uma integração de inúmeros 
fatores políticos, legais e, principalmente, culturais para que a violência seja desnaturalizada pela sociedade. Os serviços de saúde públicos e privados têm sua importância na notificação desses casos de violência, não considerando este ato como denúncia e sim um instrumento de garantia de direitos (ARANEGA, AM, et al., 2010).

Pelo contexto de luta contra este tipo de violência e sua visibilidade conquistada, qualificando-a como uma forma de violação dos direitos humanos e como um comportamento criminal, a violência contra a mulher deve ser encarada desta maneira pelos profissionais que lidam com as vítimas (GARBIN CAS, et al., 2016).

Portanto, faz-se necessário conhecer o perfil e o contexto das vítimas de violência de gênero, para que gestores públicos possam direcionar suas ações de maneira estratégica e eficaz, gerando subsídios para o aperfeiçoamento de propostas voltadas para o correto atendimento e encaminhamento das vítimas a serviços que melhor se adequem à situação de violência (BERNARDINO IM, et al., 2017).

As vítimas da situação de violência apresentam, além do dano à estrutura corporal, agravos e transtornos psicológicos, procurando, com frequência, nestas situações, hospitais e centros de saúde. Os profissionais dos serviços básicos de saúde são importantes na detecção do problema e na assistência dessas mulheres (SCHRAIBER L, et al., 2003). Neste contexto, a presença do cirurgião dentista, para avaliação das lesões do complexo maxilofacial em mulheres é indispensável na constatação e reparo dos danos advindos da violência.

Diante desta realidade e devido à carência de trabalhos que organizem os estudos a respeito da violência física contra a mulher e suas consequências com ênfase nos traumas da região maxilofacial, o presente trabalho teve como questão norteadora: Quais os principais tipos de traumatismos maxilofaciais em mulheres vítimas de violência física identificados na literatura?

O objetivo desse estudo foi descrever os principais tipos de traumas causados em mulheres por violência física, sua prevalência na região do complexo maxilofacial, além de discutir os fatores que estão relacionados com este cenário e abordar a importância da atuação do cirurgião dentista no atendimento, identificação, prevenção dos agravos na saúde da mulher vítima da violência física.

\section{MÉTODOS}

Trata-se de uma revisão integrativa de literatura realizada nas seguintes bases de dados: Literatura Latino-Americana e do Caribe em Ciências da Saúde (LILACS), Medical Literature Analysis and Retrieval System Online (MEDLINE) e Scientific Electronic Library Online (SciELO) considerando como descritores: "violência contra a mulher ", "traumas craniofaciais", "odontologia".; tendo como critérios de inclusão: artigos disponíveis na íntegra das bases, no período de 2012 a 2019, publicados nos idiomas português e inglês.

Foram excluídos teses e dissertações, artigos pagos, artigos de revisão sistemática e integrativas, publicações duplicadas, artigos repetidos ou que não tiverem relação com a temática. Após a aplicação de tais critérios de inclusão, foi realizada a leitura do título e resumo de cada artigo, com o objetivo de verificar sua adequação com a questão norteadora do presente trabalho, o que propiciou a organização de todo 0 material obtido, com cada artigo sendo disposto em uma tabela contendo título da pesquisa, autores e ano de publicação, abordagem metodológica, periódico e contribuição de estudo.

\section{RESULTADOS E DISCUSSÃO}

No presente estudo analisou-se 10 artigos que atenderam aos critérios de inclusão e exclusão previamente estabelecidos (Figura 1). De acordo com o delineamento da pesquisa $80 \%$ da amostra foi encontrada na Scientific Electronic Library Online (SciELO) ( $n=8)$, ao passo que $10 \%$ proveio da base de dados LILACS $(n=1)$, e10\% na PUBMED $(n=1)$. Dentre os artigos selecionados, $10 \%$ foram publicados em 2018 ( $n=1), 20 \%$ em 2017 (n=2), 20\% em 2015 (n=2), 30\% em 2014 (n=3), 10\% em 2012 (n=1) e 10\% em $2013(n=1)$ (Tabela 1). 
Figura 1 - Fluxograma representativo da seleção dos artigos incluídos na revisão integrativa.

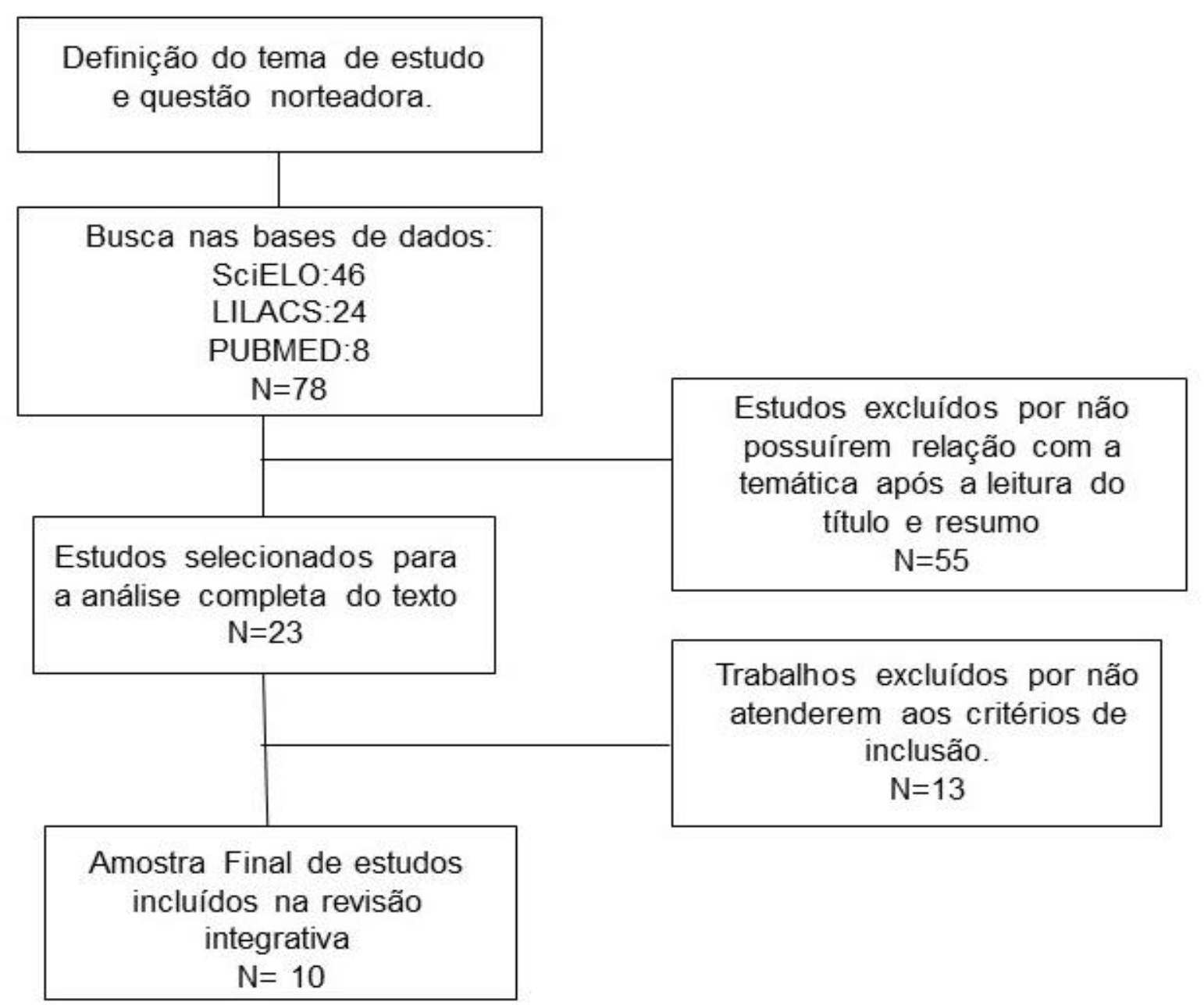

Fonte: Lago EC, et al., 2020. 
Tabela 1 - Número, título da pesquisa, autores/ano, abordagem metodológica, periódicos e contribuição dos artigos selecionados ( $n=10)$.

\begin{tabular}{|c|c|c|c|c|c|}
\hline № & Título da pesquisa & $\begin{array}{l}\text { Autores e } \\
\text { ano }\end{array}$ & $\begin{array}{l}\text { Abordagem } \\
\text { metodológica }\end{array}$ & Periódicos & Contribuição do Estudo \\
\hline 1 & $\begin{array}{l}\text { Facial traumas among females through } \\
\text { violent and non-violent Mechanisms }\end{array}$ & $\begin{array}{l}\text { COSTA } \\
\text { MCF, et al., } \\
2014\end{array}$ & $\begin{array}{l}\text { Estudo retrospectivo } \\
\text { observacional }\end{array}$ & $\begin{array}{l}\text { Brazilian Journ } \\
\quad \text { al of } \\
\text { Otorhinolaryngology }\end{array}$ & $\begin{array}{c}\text { Maior prevalência de Injúrias de tecidos moles } \\
(67,6 \%) \text { em mecanismos violentos contra } \\
\text { mulheres. }\end{array}$ \\
\hline 2 & $\begin{array}{l}\text { Patterns, aetiology and risk factors of } \\
\text { intimate partner violence-related } \\
\text { injuries to head, neck and face in } \\
\text { Chinese women }\end{array}$ & $\begin{array}{l}\text { WONG JY, } \\
\text { et al., } 2014\end{array}$ & $\begin{array}{l}\text { Transversal e } \\
\text { Retrospectivo }\end{array}$ & BMC Women's Health & $\begin{array}{l}\text { Alta prevalência em traumatismos faciais por } \\
\text { episódios de violência contra mulheres } \\
\text { representado por } 77,6 \% \text {. Dentre os } \\
\text { explanados, existe o maior índice de } \\
\text { traumatismos de tecidos moles ( } 72,5 \%), 27 \% \\
\text { de fraturas ósseas em região de face e } 0,5 \% \\
\text { de traumatismos dentários. }\end{array}$ \\
\hline 3 & $\begin{array}{l}\text { Marcas visíveis e invisíveis: danos ao } \\
\text { rosto feminino em episódios de } \\
\text { violência conjugal }\end{array}$ & $\begin{array}{l}\text { DOURADO } \\
\text { SM, } \\
\text { NORONHA } \\
\text { CV, } 2015\end{array}$ & $\begin{array}{l}\text { Descritiva e } \\
\text { transversal }\end{array}$ & $\begin{array}{l}\text { Revista Brasileira de } \\
\text { Ciências da Saúde }\end{array}$ & $\begin{array}{l}\text { Prevalência de } 62,3 \% \text { de traumatismos na } \\
\text { região do complexo bucomaxilofacial em casos } \\
\text { de violência contra a mulher. }\end{array}$ \\
\hline 4 & $\begin{array}{c}\text { Violência de gênero contra a mulher: } \\
\text { perfil de registros policiais da gerência } \\
\text { executiva de medicina e odontologia } \\
\text { legal (GEMOL) }\end{array}$ & $\begin{array}{l}\text { DIAS IJ e } \\
\text { SANTIAGO } \\
\text { BM, } 2014\end{array}$ & $\begin{array}{l}\text { Estudo quantitativo, } \\
\text { documental, analítico } \\
\text { e transversal }\end{array}$ & $\begin{array}{l}\text { Revista Brasileira de } \\
\text { Ciências da Saúde }\end{array}$ & $\begin{array}{l}\text { Predominância de lesões classificadas como } \\
\text { leves. Prevalência de traumatismos de } 45 \% \text {, } \\
\text { sendo em sua maioria nos tecidos moles } \\
(92,5 \%) \text {, seguido de fraturas ósseas }(3,8 \%) \text { e } \\
\text { traumatismos dentários. }\end{array}$ \\
\hline 5 & $\begin{array}{l}\text { Violência contra a Mulher e } \\
\text { Consequências à Saúde Bucal }\end{array}$ & $\begin{array}{l}\text { NASCIMEN } \\
\text { TO LS, et } \\
\text { al., } 2012\end{array}$ & $\begin{array}{l}\text { Transversal } \\
\text { quantitativa }\end{array}$ & Gênero na Amazônia & $\begin{array}{l}\text { Demonstra a prevalência de trauma facial em } \\
\text { 23,59\%. Danos em lábios, luxação dentária, } \\
\text { fratura parcial de coroa, perda de elementos } \\
\text { dentários são algumas lesões apresentadas } \\
\text { pelas vítimas. }\end{array}$ \\
\hline
\end{tabular}

REAS/EJCH | Vol.12(9) | e3808 | DOI: https://doi.org/10.25248/reas.e3808.2020 Página 5 de 10 


\begin{tabular}{|c|c|c|c|c|c|}
\hline 6 & $\begin{array}{c}\text { Violência interpessoal, circunstâncias } \\
\text { das agressões e padrões dos traumas } \\
\text { maxilofaciais na região metropolitana } \\
\text { de Campina Grande, Paraíba, Brasil } \\
\text { (2008-2011) }\end{array}$ & $\begin{array}{l}\text { BERNARDI } \\
\text { NO IM, et } \\
\text { al., } 2017\end{array}$ & $\begin{array}{l}\text { Estudo de } \\
\text { delineamento } \\
\text { transversal e } \\
\text { exploratório }\end{array}$ & $\begin{array}{l}\text { Revista Ciência e } \\
\text { Saúde Coletiva }\end{array}$ & $\begin{array}{l}\text { Prevalência de traumas faciais advindas de } \\
\text { agressões usando força física ou objetos } \\
\text { contundentes resultando em lesões de tecido } \\
\text { moles da face classificadas como leves. } \\
\text { Sinais clínicos mais comuns: cortes, } \\
\text { hematomas ou edemas na região facial. }\end{array}$ \\
\hline 7 & $\begin{array}{l}\text { Characterization of women victims of } \\
\text { violent death in a metropolitan area of } \\
\text { Northeast Brazil }\end{array}$ & $\begin{array}{l}\text { OLIVEIRA } \\
\text { MCA, et al., } \\
2015\end{array}$ & Estudo quantitativo & $\begin{array}{l}\text { Revista Gaúcha de } \\
\text { Odontologia }\end{array}$ & $\begin{array}{c}\text { Maior ocorrência de politraumatismos ( } 29,1 \%) \text {, } \\
\text { seguido de lesões no complexo crânio-facial } \\
26,3 \% \text {. Dentro do complexo crânio-facial a } \\
\text { cabeça foi a mais atingida com } 27,4 \% \text {. A face } \\
\text { apresentou } 4,2 \% \text { dos casos. }\end{array}$ \\
\hline 8 & $\begin{array}{l}\text { Características clinicoepidemiológicas } \\
\text { del trauma maxilofacial por violencia } \\
\text { física contra la mujer }\end{array}$ & $\begin{array}{l}\text { FERNÁNDE } \\
\text { Z FJM, } \\
\text { CARDERO } \\
\text { A, } 2014\end{array}$ & $\begin{array}{l}\text { Estudo transversal e } \\
\text { descritivo }\end{array}$ & Medisan & $\begin{array}{c}\text { Prevalência de lesões em terço médio da face } \\
(59,2 \%) \text {. A maioria das lesões afetaram os } \\
\text { tecidos moles da face }(87,3 \%) .\end{array}$ \\
\hline 9 & $\begin{array}{l}\text { Violence against women: caracteristics } \\
\text { of head and neck injuries }\end{array}$ & $\begin{array}{l}\text { CASTRO } \\
\text { TL, et al., } \\
2017\end{array}$ & $\begin{array}{l}\text { Estudo descritivo e } \\
\text { retrospectivo }\end{array}$ & $\begin{array}{l}\text { Revista Gaúcha de } \\
\text { Odontologia }\end{array}$ & $\begin{array}{l}\text { Lesões craniofaciais mais frequentes: } \\
\text { equimoses e abrasões, apresentadas nas } \\
\text { regiões orbital, cervical e frontal. }\end{array}$ \\
\hline 10 & $\begin{array}{l}\text { Análise pericial das lesões situadas em } \\
\text { cabeça e pescoço de mulheres vítimas } \\
\text { de violência doméstica atendidas em } \\
\text { um instituto médico legal de Maceió-AL }\end{array}$ & $\begin{array}{l}\text { SOARES } \\
\text { EMG, et al., } \\
2018\end{array}$ & $\begin{array}{c}\text { Estudo } \\
\text { Quantitativo }\end{array}$ & $\begin{array}{l}\text { Revista Brasileira de } \\
\text { Odontologia Legal - } \\
\text { RBOL }\end{array}$ & $\begin{array}{l}\text { Traumas na região da cabeça: lesões de } \\
\text { equimose, escoriação e edema, representando } \\
\text { mais da metade das lesões, sendo } 69,93 \% \text { e } \\
75,69 \% \text { respectivamente. }\end{array}$ \\
\hline
\end{tabular}

Fonte: Lago EC, et al., 2020.

REAS/EJCH | Vol.12(9) | e3808 | DOI: https://doi.org/10.25248/reas.e3808.2020 Página 6 de 10 
De acordo com a literatura coletada, sobre o contexto da violência física em mulheres e o perfil das vítimas e agressores, Bernardino IM, et al. (2017) afirmam que a violência contra a mulher se mostra persistente no cenário brasileiro, mesmo com medidas protetivas voltadas para as vítimas, a exemplo da Lei Federal $\mathrm{n}^{\circ}$ 11.340, conhecida como Lei Maria da Penha, não sendo esta suficiente para o enfrentamento deste problema de saúde pública no país.

As características sociodemográficas e as circunstanciais são importantes na vitimação por traumas bucomaxilofaciais em episódios de agressão, sendo as mulheres mais propensas a este tipo de violência, principalmente em ambiente doméstico, e a sustentarem lesões em tecidos da face e outras regiões do corpo.

Fernández FJM e Cardero A (2014) afirmam que os motivos das agressões estão intimamente relacionados ao cenário onde ocorrem, dependendo de fatores como: costumes e tradições, nível sociocultural, possibilidades econômicas e ambiente familiar, prevalecendo ocorrências em sociedades periféricas.

Em seu estudo, destacam as causas mais comuns desses tipos de violência, através de uma pesquisa descritiva e transversal realizada com pacientes atendidas na urgência do Hospital Provincial Docente Clinico-cirúrgico de Cirurgia Maxilofacial, enfatizando a predominância de ciúmes e embriaguez como as causas de maus tratos. Dados similares aos encontrados por Dias IJ e Santiago BM (2014), que referiram o ciúme, raiva, embriaguez alcoólica e uso de drogas ilícitas como causas desencadeadoras de violência física contra vítimas femininas.

Dados referentes aos episódios de violência contra a mulher demonstraram que o fato ocorreu, predominantemente, na própria residência da agredida $(66,2 \%)$, sendo estes praticados por parceiros íntimos das vítimas (70,3\%) (DOURADO SM, NORONHA CV, 2015). Dias IJ e Santiago BM (2014) indicaram que $33,4 \%$ das mulheres com traumatismo sofreram agressão pelo companheiro, sendo que, a maioria delas não possuíam nenhum vínculo matrimonial, ou seja, solteiras $(55,9 \%)$.

Fernández FJM e Cardero A (2014) reportaram a agressão física às mulheres perpetradas por esposos e ex-esposos ou parentes próximos das vítimas retratadas, dado este, similar às pesquisas de Bernardino IM, et al. (2017), em que reafirmam a participação do companheiro ou ex-companheiro como agressores nos casos de violência de gênero. Pode-se então afirmar, portanto, que a literatura apresenta-se homogênea quanto a significante relação entre agressor e vítima.

Sobre a ocupação das mulheres envolvidas em situações de violência física, Castro TL, et al. (2017) e Dias IJ e Santiago BM (2014) reportaram em seus estudos que as vítimas eram donas de casa e realizavam apenas trabalhos domésticos, em estado de inatividade profissional no período em que foram agredidas. Soares EMG, et al. (2018) afirmam que, dentre os episódios de agressão, os percentuais mais elevados são de mulheres que possuem menor nível de escolaridade.

Dentre os estudos feitos, somente Dourado SM e Noronha CV (2015) mostram um resultado diferente, afirmando que a maioria das mulheres $(59,1 \%)$ exercia um trabalho remunerado e haviam estudado de 5 a 9 anos completos. Em pesquisa acerca da violência interpessoal em um Centro de Medicina e Odontologia Forense, Bernardino IM, et al. (2017) reuniram um grupo de vítimas de violência física, constituído por mulheres adultas com faixa etária igual ou superior a 20 anos, sendo esta, uma faixa etária comum entre os estudos coletados, tal como apresenta Dias IJ e Santiago BM (2014), com a faixa etária de 19 a 24 anos.

Para Dourado SM e Noronha CV (2015), a média de faixa etária permeia entre 20 e 39 anos. Castro TL, et al. (2017) apresentam a faixa etária de 20 a 30 anos como mais frequente, dando ênfase às idades apresentadas, por representar um dado preocupante ao incluir uma fase importante na vida da mulher relacionado ao seu período reprodutivo e também com o cuidado dos filhos.

Quanto ao estado civil das vítimas relatadas nos estudos, existe uma divergência de resultados da literatura selecionada. Nascimento LS, et al. (2012) constataram em sua pesquisa em igual percentual mulheres solteiras e casadas (29\%), Dias IJ e Santiago BM (2014), demonstraram a prevalência de mulheres solteiras ou sem contrato civil estabelecido (55,9\%), demonstrando contraste significante com o trabalho de Bernardino IM, et al. (2017) ao reportar em maior número mulheres casadas, como as mais comuns nos casos de violência física. 
Outra questão importante, obtida através dos estudos coletados, traz como temática os traumatismos maxilofaciais em mulheres vítimas de agressão, onde é afirmado que, a face geralmente é a única parte do corpo que não pode ser coberto, é o centro das relações humanas, onde se é capaz de identificar as características genéticas, expressões, idade, entre várias outras características do ser humano (MELLOFILHO FV, et al., 2014). Dados epidemiológicos apresentam consonância ao relatar nos casos de violência física de gênero, a região de cabeça, particularmente a face como principal alvo das agressões (DOURADO SM, NORONHA CV, 2015).

Voltado para a violência doméstica contra a mulher, é contabilizado em cerca de 34 a $76 \%$ sua incidência nas vítimas. $O$ culto à beleza, comum nos dias atuais, principalmente nas mulheres, produz a não aceitação de possíveis sequelas geradas pelo trauma na face (MELLO-FILHO FV, et al., 2014).

Os estudos coletados demonstraram a prevalência de traumatismos maxilofaciais, causados por episódios de violência contra a mulher. Dentre os estudos realizados no cenário brasileiro, a prevalência compreende de $23,6 \%$ a $62,6 \%$. Já no cenário internacional, apresentado por Wong JY, et al. (2014) mostra uma alta prevalência, representada por $77,6 \%$ desses traumas. Nascimento LS, et al. (2012) reportaram que $23,1 \%$ das vítimas de violência física sofreram traumas maxilofaciais, representando que, a cada 4 mulheres vítimas de violência, 1 possuía trauma na região da face. Dourado SM e Noronha CV (2015) constataram em pesquisa, a prevalência de $63,2 \%$ de traumas na face, cabeça ou região de pescoço. Somente no estudo de Oliveira MCA, et al. (2015), o trauma facial não ocupou a maior prevalência nas manifestações de violência contra mulher, sendo esta ultrapassada pela prevalência de politraumatismos representado por $29,1 \%$, seguido de lesões no complexo crânio facial $(26,3 \%)$ ocupando a segunda maior prevalência de lesões.

A respeito dos tipos de traumas e seus locais mais frequentes na região maxilofacial, a coleta feita revelou a predominância de lesões de grau leve, localizadas em região de tecidos moles (BERNARDINO IM, et al., 2017; DIAS IJ e SANTIAGO BM, 2014; WONG JY, et al., 2014).

Castro TL, et al. (2017) reportaram lesões extra e intraorais, sendo a primeira centrada em várias regiões da cabeça, face e pescoço, os mais afetados representados pela região orbital (17,14\%), e frontal $(12,51 \%)$. Porém, é posto em evidência um significante domínio na ocorrência das lesões de equimoses (28.85\%) e abrasão $(25,6 \%)$ na região tecido mole. As lesões intraorais, principalmente dento-alveolares se mostram pouco frequentes nos estudos coletados. Dados similares foram encontrados na pesquisa de Soares EMG, et al. (2018), demonstrando a predominância da lesão de equimose $(69,93 \%)$ e escoriações.

Bernardino IM, et al. (2017) reafirmam as lesões de tecidos moles como mais relatadas, ainda discorre sobre os sinais clínicos mais comuns, sendo estes cortes, hematomas e edemas na região de face, podendo estes sinais serem manifestados também, em outras regiões do corpo.

No cenário internacional, laudos examinados por Wong JY, et al. (2014), em um Hospital de referência em Hong Kong confirmam lesões do complexo cabeça pescoço geralmente do tipo leve, as lesões afetando tecido mole na forma de contusão (representando $28 \%$ da amostra), abrasão (16\%), inchaço (10\%), eritema $(7 \%)$, hematoma $(6 \%)$, laceração $(5 \%)$, entre outras envolvendo sangramento nasal, e dentário, sem envolver fratura.

Quanto às lesões buco-dentárias, sua classificação e predominância foi considerada significativa somente por Dias IJ e Santiago BM (2014), e Nascimento LS, et al. (2012), representando para o primeiro citado, $78,5 \%$ de sua amostra. Traumatismos, avulsões dentárias (apresentando fratura parcial e total de coroa e raiz) e disfunções têmporo-mandibulares foram citados nos tipos de lesões encontradas com menor frequência.

Em caso de homicídios contra mulheres, por violência, estudado por Oliveira MCA, et al. (2015), através de laudos necroscópicos, a localização topográfica das lesões foi concentrada na área região labial, seguida da região do nervo mentoniano, bucinador, orbital e frontal.

Dourado SM e Noronha CV (2015) coletaram dados de forma singular, classificando, em sua amostra com mulheres vítimas de violências afetadas por lesões em face e/ou cabeça e/ou pescoço (lesões FCP), a prevalência de lesões na cabeça incluídas como traumas bucomaxilofaciais em região orbital, têmpora e pescoço da vítima, incluindo ao último, casos de trauma na mandíbula ou abaixo do queixo. 
No que se refere à importância do cirurgião dentista no contexto de violência contra a mulher, os trabalhos afirmam que, por ser um problema de saúde pública, o tema abordado merece atenção dos profissionais da área de saúde, que devem estar preparados para acolher, realizar o tratamento e escuta ativa com as mulheres violentadas, além disso, devem estar aptos a fazer o atendimento humanizado, adequado e compreender o percurso necessário para o encaminhamento das vítimas (SANTOS WJ, et al., 2018).

A odontologia e os profissionais da área não podem ignorar e muito menos aceitar a violência como fato corriqueiro e pertinente a outras áreas de saúde. É de suma importância reconhecer as consequências físicas geradas e refletir a respeito com responsabilidade, preocupando-se com a prevenção, intervindo e posicionando-se no combate à violência (NASCIMENTO LS, et al., 2012).

Ressalta-se a grande importância da Odontologia e suas especialidades, com ênfase na Odontologia Legal para o exame, análise pericial, responsáveis pela construção de laudos que auxiliam a justiça em decisões legais, além de ajudar a compor dados estatísticos que colaboram na prevenção e promoção relacionadas ao combate à violência contra as mulheres (SOARES EMG, et al., 2018).

Em casos semelhantes aos citados neste trabalho, as necessidades em saúde das mulheres vítimas exigem uma atuação multidisciplinar. Dentre essa equipe, o cirurgião dentista ocupa um espaço muito importante, pois por meio de sua capacitação para lidar com a mulher vítima da violência, pode, além de prestar assistência em saúde, de forma integral, reforçar que as demandas deste tipo de violência ultrapassam as questões voltadas para a saúde, necessitam de ações em rede, incluindo a segurança pública e judiciária. Desta forma, é imprescindível o conhecimento do cirurgião dentista a respeito do fluxo destas redes que garantem a proteção daquelas que estão sob a situação de agressão (DOURADO SM, NORONHA CV, 2015).

No Brasil, a notificação compulsória dos casos de violência física contra a mulher, que for atendida em serviços de saúde públicos e privados, é estabelecida pela Lei no 10.778 , de 24 de novembro de 2003. A realização da notificação dos casos de violência física pelo cirurgião dentista ou outro profissional da saúde é de suma importância para o enfrentamento do fenômeno da violência física e as consequências desta na vida das mulheres (BRASIL, 2003).

Contudo, a literatura estudada aponta que existe uma dificuldade entre os profissionais da saúde ao investigar, identificar e registrar traumas advindos de agressão, pela omissão das vítimas sobre o fator etiológico, devido ao constrangimento, bem como fatores emocionais que a limitam de explicar os motivos que levaram ao ato de agressão.

Ao omitirem informações a respeito do episódio de agressão essas mulheres ficam mais expostas aos fatores de risco, e os casos não relatados acabam por limitar as ações dos profissionais de saúde em relação ao atendimento inicial e posteriores procedimentos (COSTA MCF, et al., 2014).

Por ser a região de cabeça e pescoço um dos sítios mais atingidos diante de atos de agressão à figura feminina, o cirurgião dentista se torna um dos profissionais que possuem grande chance de ter contato direto com as vítimas, se tornando agente efetivo na identificação, prevenção e atendimento dos agravos do complexo maxilomandibular à saúde das vítimas de violência (DIAS IJ e SANTIAGO BM, 2014).

\section{CONSIDERAÇÕES FINAIS}

Evidenciou-se no estudo, uma grande prevalência de traumatismos na região maxilofacial relacionados à violência física contra a mulher, classificados como leves, e localizados principalmente na região dos tecidos moles. Os estudos demonstram dados não somente relacionado às injúrias presentes nas vítimas da violência de gênero, como também, reportar as circunstâncias em que são perpetradas essas agressões, contribuindo para o avanço do conhecimento neste campo. Tal revisão procurou enfatizar a importância do cirurgião dentista inserido no contexto da violência contra a mulher, sendo este, sujeito protagonista no tratamento dos traumas maxilofaciais apresentados, na prevenção e notificação dos casos intervindo e posicionando-se no combate à violência. 


\section{REFERÊNCIAS}

1. ARANEGA AM, et al. Etiologia e incidência de traumas faciais relacionados à violência doméstica à mulher. Revista LEVS, 2010; 5(5): 118-124.

2. BERNARDINO IM, et al. Violência interpessoal, circunstâncias das agressões e padrões dos traumas maxilofaciais na região metropolitana de Campina Grande, Paraíba, Brasil (2008-2011). Ciência \& Saúde Coletiva, 2017; 22: 3033-3044.

3. BRASIL. Lei $n . \stackrel{0}{10.778}$, de 24 de novembro de 2003. Brasília: Diário Oficial da União; 2003.

4. CASTRO TL, et al. Violence against women: caracteristics of head and neck injuries. RGO-Revista Gaúcha de Odontologia, 2017; 65(2): 100-108.

5. CHAVES AS, et al. Prevalência de traumatismos maxilofaciais causados por agressão ou violência física em mulheres adultas e os fatores associados: uma revisão de literatura. Revista da Faculdade de Odontologia - UPF, 2018; 23 (1): 60-67.

6. COELHO EBS, et al. Violência: definições e tipologias. Florianópolis: Universidade Federal de Santa Catarina, 2014; 32p.

7. COSTA MCF, et al. Facial traumas among females through violent and non-violent mechanisms. Brazilian Journal of Otorhinolaryngology, 2014; 80(3): 196-201.

8. DIAS IJ, SANTIAGO BM. Violência de gênero contra a mulher: perfil de registros periciais da Gerência Executiva de Medicina e Odontologia Legal (GEMOL) João Pessoa/PB. Revista Brasileira de Ciências da Saúde, 2014; 18(4): 315-324.

9. DOURADO SM, NORONHA CV. Marcas visíveis e invisíveis: danos ao rosto feminino em episódios de violência conjugal. Ciência \& Saúde Coletiva, 2015; 20: 2911-2920.

10. FERNÁNDEZ FJM, CARDERO A. Características clinicoepidemiológicas del trauma maxilofacial por violencia física contra la mujer. Medisan, 2014; 18(12): 1652-1660.

11. GARBIN CAS, et al. Percepção e atitude do cirurgião-dentista servidor público frente à violência intrafamiliar em 24 municípios do interior do estado São Paulo, 2013-2014. Epidemiologia e Serviços de Saúde, 2016; 25: 179-186.

12. KRUCZEWSKI B, PEREIRA RW. Perfil da violência contra a mulher em Santa Catarina. Anais de Medicina. $3^{3}$ ed. 2016.

13. MELLO-FILHO FV, et al. Epidemiological modifications of facial trauma and its implications. Brazilian Journal of Otorhinolaryngology. 2014; 80(3): 187-188.

14. NASCIMENTO LS, et al. Violência contra mulher e consequências à saúde bucal. Gênero na Amazônia, 2012; 2 , jul-dez.

15. NETTO LA, et al. Violência contra a mulher e suas consequências. Acta Paulista de Enfermagem, 2014; 27(5): 458-464.

16. OLIVEIRA MCA, et al. Characterization of women victims of violent death in a metropolitan area of Northeast Brazil. RGO-Revista Gaúcha de Odontologia, 2015; 63(4): 439-445.

17. ORGANIZAÇÃO DAS NAÇÕES UNIDAS-(ONU). Declaração sobre a eliminação da violência contra as mulheres. Resolução $n^{\circ}$ 48/104, 20 de dezembro de 1993 [sob proposta da Terceira Comissão (A/48/629)], 85a sessão plenária. Nova York: ONU, 1993.

18. SANTOS WJ, et al. Violência Doméstica Contra a Mulher Perpetrada por Parceiro Íntimo: Representações Sociais de Profissionais da Atenção Primária à Saúde. Journal of Research: Fundamental Care Online, 2018; 10(3): 770777.

19. SCHRAIBER L, et al. Violência vivida: a dor que não tem nome. Interface - Comunicação, Saúde, Educação, 2003; 7(12): 41-54.

20. SOARES EMG, et al. Análise pericial das lesões situadas em cabeça e pescoço de mulheres vítimas de violência doméstica atendidas em um instituto médico legal de Maceió-AL. RBOL-Revista Brasileira de Odontologia Legal, 2018; 5(3): 12-22.

21. WONG JY, et al. Patterns, aetiology and risk factors of intimate partner violence-related injuries to head, neck and face in Chinese women. BMC Women's Health, 2014; 14(6): 1-9. 